The importance of understanding this topic is summed up in the following statement by the author: 'To undertake the best treatment for the patient, one must first understand what is normal to gain better awareness of the abnormal.' I believe that this text achieves this. I can therefore highly recommend it as a core resource to be used at all stages of dental undergraduate and postgraduate training.

S. Liyanage

\section{HOW CAN I KNOW MY CHILD'S DENTITION?}

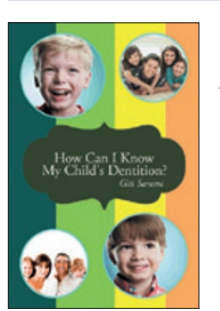

\section{G. Sarami}

AuthorHouse

price Ł8.95; pp 48

ISBN 9781481783996

Aimed at parents, this text attempts to increase their understanding of their child's dentition. The author appears enthusiastic in an effort to educate those parents interested enough in improving their basic dental knowledge.

What initially seems an excellent idea disappointingly falls short in several areas. Worryingly, each chapter is littered with grammatical errors. One cannot help but feel confused about the messages it is trying to portray, due to the contradictory advice given throughout. To confound matters, as a text aimed at non-dental professionals an abundance of complex dental terminology only adds to the confusion.

The text is broken up into seven short chapters. The first discusses factors that influence a child's behaviour in the dental surgery, focusing on the way children pick up on parental anxieties.

The next two chapters give a brief explanation of the development of both primary and permanent dentitions and the anatomy of tooth structure. There is good advice on natal teeth and descriptions of the normal eruption patterns and reasons for deviations from the norm.

Chapter four, 'Causes of tooth decay', lists varying causative factors in hierarchical order of importance according to the author. Alarmingly, this list doesn't include dietary factors or oral hygiene measures, only stating at the end that 'it is important not to eat a lot of sweets and sticky toffees.' There is also a misconstrued message that fillings should be assessed every five to six years, which doesn't promote the importance of regular dental visits.

Chapter five is a useful chapter on prevention. It describes the various preventive measures available, fluoride therapies and oral hygiene techniques. However, the chapter contradicts itself in the most important message it is trying to portray. Initially stating 'for children under six, brushing with a toothbrush and water only is recommended', it then goes on to describe the use of fluoride toothpaste for children as young as one. This can only confuse readers.

The book finishes with short chapters on the restoration of teeth and traumatic injuries. These describe the use of local anaesthetic and the different types of injuries that may occur, with some possible outcomes.

I believe the book could be improved with some simple additions. The use of colour images would go a long way in helping explain things clearly, along with a glossary of terms.

This text provides a lot of useful information for eager parents and the author's mission to educate those interested is commendable. With an easy-to-read layout and short concise chapters, it offers great potential. Unfortunately, due to the numerous shortcomings and conflicting messages, it is difficult to recommend.

E. Nugent

\section{THE PRINCIPLES OF ENDODONTICS, 2ND EDITION}

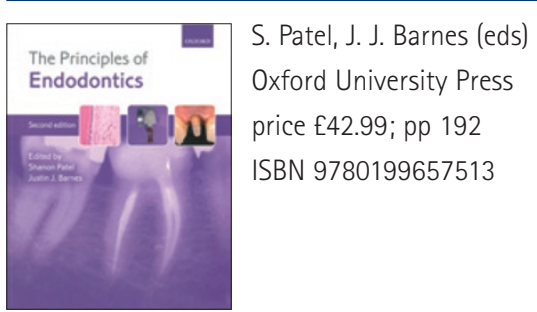

The second edition of The principles of endodontics has been worth the wait since the publication of the first edition back in 2005. This book is aimed at undergraduate dental students, recent graduates and GDPs wishing to refresh their knowledge with more contemporary techniques and information.

The book is organised into ten chap- ters taking the reader through a logical and systematic approach to endodontics, starting from a short introduction to tooth development, diagnosis, pulp preservation, root canal techniques, restoration and finally managing posttreatment disease.

There is in addition copious use of fantastic high quality images, radiographs and diagrams that makes it useful for OSCE exams.

Summary boxes can be found at the end of each chapter; perfect for someone wishing for a quick glance at the main features of the chapter or to summarise what one has read. Also available is an online interactive resource centre, via an internet link at the end of each chapter, allowing the reader to test their knowledge.

The book is planned and designed well, making it easy to read. There is good use of text boxes giving information in concise bullets points, which makes it useful for revision for undergraduates.

Clinical scenarios and techniques can be visualised well due to the step-bystep diagrams and clinical photos. This is especially useful again for undergraduates and newly qualified dentists when the depth of experience in the field is limited.

The authors decided to keep references to a minimum, inviting readers to explore their list of further reading at the end of each chapter. This is a good idea and the suggested reading list consists of scientific journals and other specialised books. However, I think keeping a moderate amount of referencing in the actual text would have made this book an even better resource for undergraduates and foundation dentists, purely because the references would be available immediately rather than the reader having to search for them somewhere else. Some will like this and others won't. It's a step in the right direction encouraging readers to explore more self-directed learning.

I would definitely recommend this book for any novice to endodontics or experienced GDP wishing to renew their knowledge. Concise, detailed, contemporary and well-delivered information makes this book a definite buy.

M. Ali 